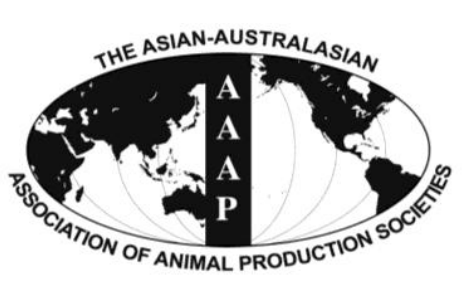

Open Access

Asian Australas. J. Anim. Sci.

Vol. 27, No. 3 : 391-397 March 2014

http://dx.doi.org/10.5713/ajas.2013.13386

www.ajas.info

pISSN 1011-2367 elSSN 1976-5517

\title{
Impact of Echinococcosis on Quality of Sheep Meat in the South Eastern Kazakhstan
}

\author{
Z. Valieva, N. Sarsembaeva, A. Valdovska ${ }^{1}$, , and A. E. Ussenbayev \\ Kazakh National Agrarian University, Faculty of Veterinary Medicine, Abay street 28, Almaty, Kazakhstan
}

\begin{abstract}
A survey of 2,123 slaughtered adult sheep in markets of the south-east Kazakhstan established that the average contamination of animals by Echinococcus granulosus is $9.1 \%$ with primary localization of cysts in livers and lungs. The histologic structure of the muscle tissue of infected sheep displayed destructive changes with a prevalence of granular dystrophy. The amount of protein, fat, calcium and energetical value of such meat considerably decreased. Besides in the muscle tissue of the animals infected with echinococcosis there was a substantial increase of humidity and amount of ash as well as qualitative and quantitative changes of the amino acids profile. Along with damage to the synthesis of proteins and sharp insufficiency of vitamins $A, E, B_{1}$, and $B_{2}$ there was a shift in a lipidic exchange that was expressed as a noticeable reduction in the level of monounsaturated and polyunsaturated fatty acids. The data support the conclusion that the meat from the sheep infected with echinococcosis is of inferior quality and quantity compared to that of healthy animals. (Key Words: Echinococcus, Sheep, Mutton, Kazakhstan)
\end{abstract}

\section{INTRODUCTION}

Cystic echinococcosis (CE), caused by Echinococcus granulosus, is an important zoonotic infection causing morbidity and mortality in humans and significant economic losses in livestock (Budke et al., 2006). It is an emerging disease in many parts of the world, particular in countries of the former Soviet Union, in Eastern Europe and in Asia (Romig et al., 2006; Torgerson et al., 2006).

The annual economic losses from echinococcosis are estimated to be approximately four billion US dollars on a global scale, and the losses are due to disability and costs of treatment of infected humans as well as animal production losses due to death of infected animals, condemnation of internal organs of slaughtered lifestock, reduction in carcass weight, decrease in milk production, fecundity and other production-based losses. Therefore, considering the importance of a problem, the World Health Organization

\footnotetext{
* Corresponding Author: A. Valdovska. Tel: +371-26525501, Fax: +371-63027344, E-mail: Anda.Valdovska@1lu.lv

${ }^{1}$ Latvia University of Agriculture, Faculty of Veterinary Medicine, K.Helmana street 8, Jelgava, LV-3001, Latvia.

Submitted Jul. 2, 2013; Accepted Sept. 29, 2013; Revised Nov. 4, 2013
}

and International Epizootic Bureau included echinococcosis in the list of the diseases which are the subject to radical eradication (Theodoropoulos et al., 2002; Budke et al., 2006; Ernest et al., 2009; Getaw et al., 2010; Borji et al., 2012).

It should be noted that in Kazakhstan and other former Soviet Union countries of Central Asia where during the last two decades there was a formation of a new economic model of agrarian production, and in these conditions a considerable increase of indicators of human's and agricultural animals' infection by $\mathrm{CE}$ was observed. Consequently, large-scale research of epidemiology and measures of prevention of this zoonosis were organized (Torgerson et al., 2002; Shaikenov et al., 2003; Torgerson et al., 2003).

However, during the specified period, reseach on the quality and the veterinary -sanitary assessment of the meat and other production parameters from animals infected by cyst echinococcosis was not practically carried out. Nevertheless, it is known that infection with parasites has an impact on animal production including meat and wool productivity and quality (Bergstrom et al., 1977; Knecht et al., 2012). It is established by standard biochemical methods that beef from cattle, infected with cystic

Copyright @ 2014 by Asian-Australasian Journal of Animal Sciences This is an open-access article distributed under the terms of the Creative Commons Attribution Non-Commercial License (http://creativecommons.org/licenses/by-nc/3.0/), which permits unrestricted non-commercial use, distribution, and reproduction in any medium, provided the original work is properly cited. 
echinococcosis, is of lower quality than the meat produced from healthy animals (Yampolskiy, 1981; Blochina, 2009).

Taking into the account that the sheep breeding is a traditional branch of animal husbandry and the mutton produced makes a significant share of a meat diet of the population in Kazakhstan, the purpose of this research has been to define the influence of the infection by echinococcosis on the quality of the muscle tissue of slaughtered sheep.

\section{MATERIALS AND METHODS}

\section{Study area and animals}

The study was conducted from January 2010 to December 2011 in the slaughterhouse in Almaty region, Kazakhstan. A total of 2,123 slaughtered sheep in age of 3 to 5 years were observed.

\section{Post mortem examination}

The veterinary examination was carried out following the requirements established in Chapter II Domestic sheep and goats of Section IV of Annex I Regulation (EC) No $854 / 2004$ of the European Parliament and of the Council of 29 April 2004 laying down specific rules for the organization of official controls on products of animal origin intended for human consumption.

During postmortem examination, organs of the abdominal and thoracic cavities namely liver, lung, heart, kidney and spleen were systematically inspected for the presence of hydatid cysts by applying the routine meat inspection procedures. Diagnosis of hydatid cysts was done macroscopically either by visual inspection or palpation and, where necessary, one or more incisions were made in order to detect small hydatid cysts.

A portion of approximately $200 \mathrm{~g}$ of Longissimus dorsi muscle from 5 clinical healthy and from 15 animals with signs of echinococcus invasion was collected and stored hermetically in closed and labeled containers and frozen to $-10^{\circ} \mathrm{C}$ until chemical analyzing (not more than 5 days).

\section{Histology}

For histological examination, sections of approximately $2.0 \mathrm{~cm}$ of $M$. longissimus dorsi from the infected and uninfected sheep were removed and immediately fixed in $10 \%$ formaldehyde solution at least $48 \mathrm{~h}$. Fixed tissues were carefully washed with water; dehydrated through a graded series of alcohol; cleared with xylene and embedded in paraffin wax. Sectioned at $5 \mu \mathrm{m}$ thick were made, mounted on glass slides and stained with hematoxylin and eosin (HE) (Carson, 1997).

\section{Meat chemical analysis}

Lipids for fat content determination were extracted from muscle tissues by the method described by Folch et al. (1957). The composition of fatty acids was defined by a methylation method (ISO 5509, 1978; AOAC, 1990) and by using a HP 69890 gas chromatograph equipped with flame ionization detector and silica capillary column HP Innowax $30 \mathrm{~m} \times 32 \mathrm{~mm} \times 0.5 \mu \mathrm{m}$.

The amino acid composition of the representative samples was determined by analyser according to AOAC (1990). Efficient methods for the extraction and determination of the water- and fat-soluble vitamins were established, and the separations were performed on the UltiMate HPLC system with Acclaim columns. HPLC method use different mobile phases and columns for waterand fat-soluble vitamins. The water-soluble vitamins were resolved on the Acclaim Polar Advantage (PA) II column using a phosphate buffer in the mobile phase. The fatsoluble vitamins were resolved on the Acclaim $120 \mathrm{C} 18$ column using an organic-solvent mobile phase.

\section{Data analysis}

Basic data entry and handling were done using MS Excel. The significance of differences among chemical values of each sample was determined by analysis of variance (ANOVA) and t-test. Prevalence of hydatidosis was calculated as the number of sheep found infected with hydatid cysts expressed as the percentage of the total number of slaughtered. Differences were considered significant at $\mathrm{p}<0.05$ level.

\section{RESULTS}

\section{Post mortem examination}

At postmortem examination, a visual inspection was made of the condition of the carcass, the head and regional lymph nodes. In carcasses of healthy animals the muscles were well developed, spinous processes of cervical, thoracic and lumbar vertebrae, tuberis ossis ischii, hips were allocated not sharply; subcutaneous fat covered the carcass from the 8th rib to tuberis ossis ischii, the neck, scapulas, forward ribs and legs, the pelvic cavity and area of a groin had fat deposits in the form of small sites. In carcasses of animals, infected by cystic echinococcosis, there were less developed muscles, prominent spinous processes of

Table 1. Dynamics of echinococcosis infection of sheep on seasons of year (2010-2011)

\begin{tabular}{lccc}
\hline \multirow{2}{*}{ Seasons } & \multicolumn{2}{c}{ Number of sheep } & Prevalence \\
& Investigated & Infected & $(\%)$ \\
\hline Winter & 228 & 24 & 10.5 \\
Spring & 376 & 46 & 12.2 \\
Summer & 658 & 48 & 7.3 \\
Autumn & 861 & 75 & 8.7 \\
Total & 2,123 & 193 & 9.68 \\
\hline
\end{tabular}


vertebrae, tuberis ossis ischii and hips, a poor development of the fatty layer was noted.

During the study, from 2,123 sheep obtained from the slaughterhouse, $193(9.1 \%)$ animals were positive for cystic echinococcosis (findings are summarized in Table 1). Contamination by hydatid cysts of sheep had rather stable character and slightly varied depending on a season of slaughter of sheep (Table 1).

The infection prevalence was rather high during the spring period and reached $12.2 \%$. In the winter the contamination of sheep was, on the average, $10.5 \%$. In the summer and autumn the prevalence was lower, $7.3 \%$ and $8.7 \%$, respectively. The average level of contamination of animals was $9.1 \%$.

The analysis of the hydatid cysts' distribution on organs of localization shows that only the liver was infected amongst majority of animals $(71.5 \%)$. The simultaneous contamination of a liver and lungs was noted at $27 \%$ of sheep (Table 2). The multiple echinococcosis with simultaneous infection of three organs was found in $1.6 \%$ of the infected animals, including a sheep with contamination of kidneys, a liver and lungs, and two individuals with cysts in a spleen, a liver and lungs. The hydatid cysts were found in the liver and lungs (Table 2, Figure 1). Cysts were mainly located in the parenchyma, close to the liver membrane which colour changed to opaque gray. Average parasites' intensity of organs was 3 to 4 cysts. The average size varied from 2 to $7 \mathrm{~cm}$; all found parasitic cysts were fertile. At an intensive invasion the infected organs considerably increased in a size and weight, the consistence was denser in comparison with healthy organs.

\section{Histology of meat}

Histologic changes of muscle tissue in all cases investigated were the same. Muscle fibers were bulked up, unevenly reinforced with poorly expressed striated
Table 2. Distribution of echinococcus cysts on organs of the infected sheep $(n=193)$

\begin{tabular}{lcc}
\hline \multirow{2}{*}{ Organs } & \multicolumn{2}{c}{ Distribution of echinococcus cysts } \\
\cline { 2 - 3 } & Number of animals & $\%$ \\
\hline Liver & 138 & 71.5 \\
Liver, lungs & 52 & 27 \\
Kidneys, liver, lungs & 1 & 0.5 \\
Spleen, liver, lungs & 2 & 1.1 \\
\hline
\end{tabular}

appiarance, the sarcoplasm contained fine-grained eosinophil mass. Nuclei of muscle fibers aren't changed in separate places, but in many sites they appear as though veiled by granular dystrophy (Figure 3). Thus, it is possible to assume that under the influence of toxins, produced by echinococcus cysts, the patomorphological changes are of a type that granular dystrophy has developed in the muscle tissue of sheep in comparison with tissue of the healthy sheep (Figure 2).

\section{Meat chemical composition}

The research of the chemical composition of muscles (Table 3) revealed that the tissue moisture content of the

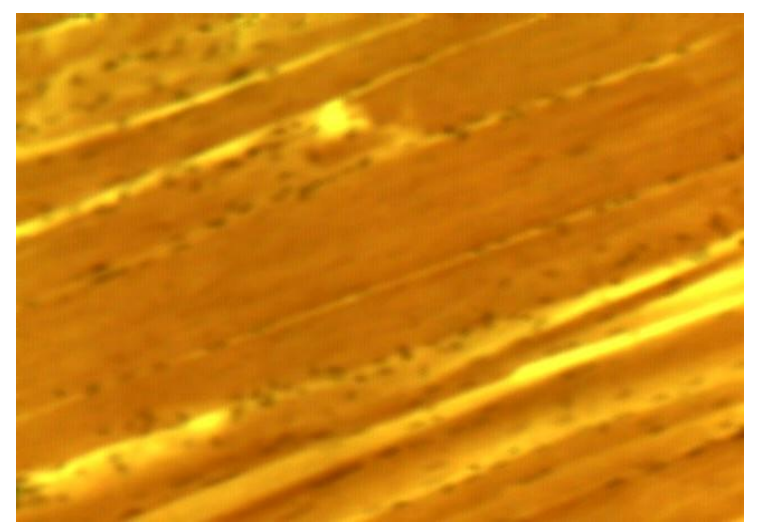

Figure 2. Histological structure of the muscle tissue of the healthy sheep.

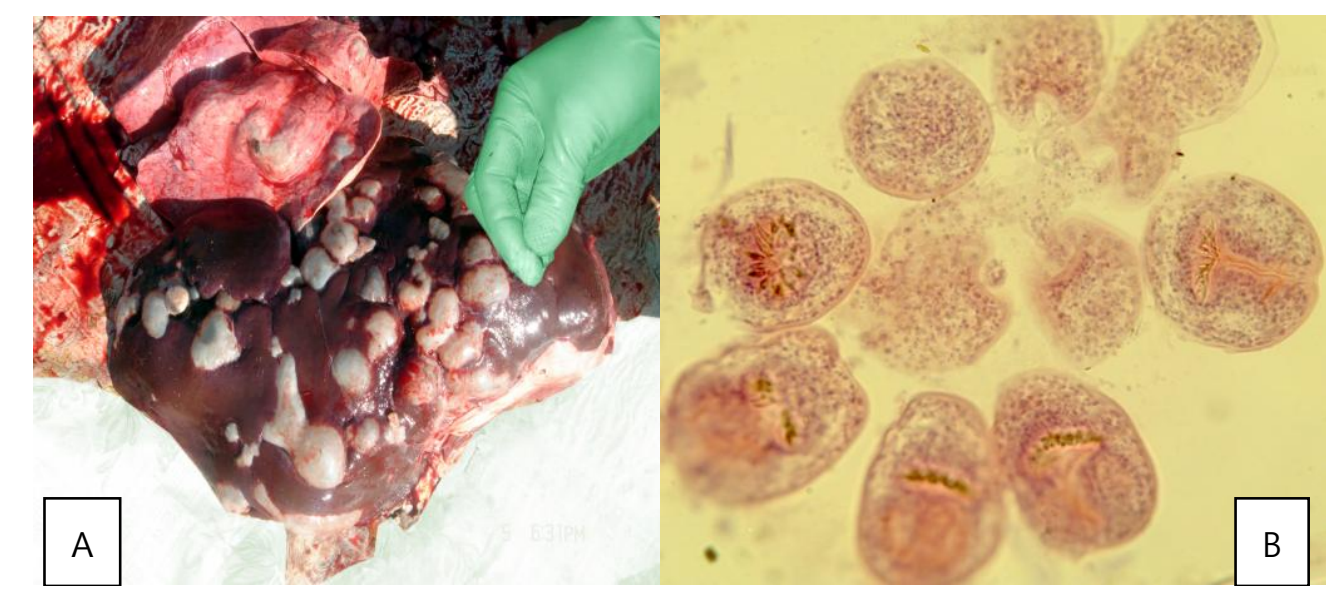

Figure 1. (A) Echinococcus granulosus cysts in sheep liver and lung. (B) Isolated protoscoleces from cysts. 


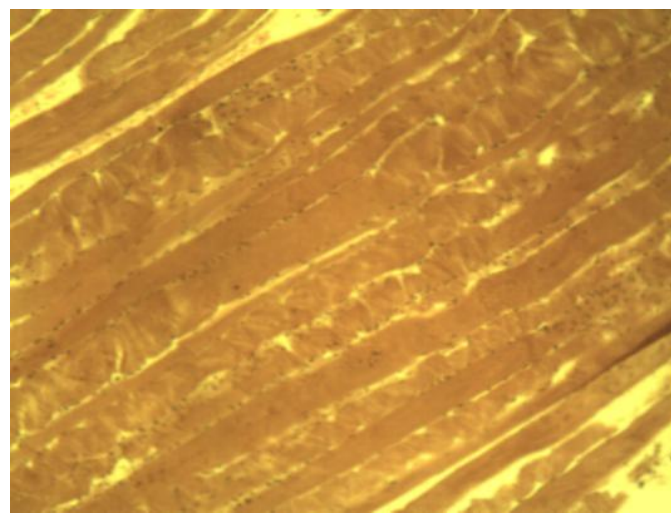

Figure 3. Pathomorphology of the sheep muscle tissue at the echinococcosis.

sheep infected with echinococcosis was increased by $8.8 \%$ $(\mathrm{p}<0.05)$ in comparison with healthy animals. Thus, there occurs a dynamic that increases the moisture content in muscles of sick animals. It is known that the cystic echinococcosis infection promotes the decrease in a protein level of animals' tissues which depends on the intensity of an invasion. According to our research, the muscle tissue of healthy sheep contains a protein average of $19.5 \mathrm{~g}$ and in infected animals this indicator was lower by $4.1 \%(\mathrm{p}<0.05)$. The content of fat in muscles of the infected animals also decreased $(\mathrm{p}<0.05)$ considerably and was $37 \%$ less than in healthy animals.

Results of our research indicate that the echinococcosis

Table 3. Nutrition value of mutton

\begin{tabular}{|c|c|c|}
\hline \multirow[b]{2}{*}{ Indicators } & \multicolumn{2}{|c|}{ Meat of animals } \\
\hline & $\begin{array}{c}\text { Infected by } \\
\text { echinococcosis }\end{array}$ & Healthy \\
\hline \multicolumn{3}{|l|}{ Nutrition value (g/100 g) } \\
\hline Proteins & $18.66 \pm 0.19$ & $19.57 \pm 0.04 *$ \\
\hline Fats & $9.24 \pm 0.44$ & $14.7 \pm 0.08 *$ \\
\hline Moisture content & $71.17 \pm 0.28^{*}$ & $64.91 \pm 0.12$ \\
\hline Ashes & $0.93 \pm 0.02 *$ & $0.82 \pm 0.02$ \\
\hline Calorific value cal/100 g & 157 & $185^{*}$ \\
\hline \multicolumn{3}{|l|}{ Vitamins (mg/100 g) } \\
\hline Vitamin A & $0.011 \pm 0.01$ & $0.026 \pm 0.01 *$ \\
\hline Vitamin E & $0.623 \pm 0.01$ & $0.844 \pm 0.03 *$ \\
\hline Vitamin PP & $3.922 \pm 0.03$ & $4.044 \pm 0.01$ \\
\hline Vitamin $\mathrm{B}_{1}$ & $0.075 \pm 0.01$ & $0.082 \pm 0.01 *$ \\
\hline Vitamin $\mathrm{B}_{2}$ & $0.131 \pm 0.01$ & $0.188 \pm 0.01 *$ \\
\hline Vitamin $\mathrm{K}$ & $315.4 \pm 0.02$ & $328.7 \pm 0.40^{*}$ \\
\hline \multicolumn{3}{|l|}{ Mineral elements (mg/100 g) } \\
\hline Calcium (Ca) & $8.7 \pm 0.07$ & $9.16 \pm 0.05 *$ \\
\hline Magnesium (Mg) & $23.3 \pm 0.12$ & $23.18 \pm 0.10$ \\
\hline Sodium $(\mathrm{Na})$ & $98.74 \pm 0.19$ & $98.7 \pm 0.25$ \\
\hline Iron $(\mathrm{Fe})$ & $1.93 \pm 0.12$ & $1.92 \pm 0.07$ \\
\hline Zinc $(\mathrm{Zn})$ & $2.62 \pm 0.21$ & $2.52 \pm 0.07$ \\
\hline
\end{tabular}

$* \mathrm{p}<0.05$ value differ significantly. has an impact on a mineral exchange too. In muscle tissue of infected animals we observed an increase in the content of ashes and decrease in the concentration of calcium. For example, in muscles of healthy sheep the share of ashes was $0.82 \mathrm{~g}$ and level of calcium reached $9.16 \mathrm{mg}$ whereas in samples from the infected animals these indicators were higher by $11.8 \%(\mathrm{p}<0.05)$ and lower for $5.0 \%(\mathrm{p}<0.05)$, respectively.

It should be noted also that the calorific value of the infected animals' meat was $15.1 \%$ lower in comparison with muscle tissue of healthy sheep, and made 157 and 185 $\mathrm{cal} / 100 \mathrm{~g}(\mathrm{p}<0.05)$, respectively. According to the obtained data, echinococcosis also considerably influences to the content of vitamins of muscle tissue. So, practically all studied vitamins in samples from infected animals were present in lower concentration than in healthy sheep. However, the strongest influence of the infection was noted on vitamins $\mathrm{A}, \mathrm{B}_{2}, \mathrm{E}, \mathrm{B}_{1}$, and $\mathrm{K}$ which contents in muscles of the infected animals was less ( $\mathrm{p}<0.05)$ for $57.7 \%, 30.3 \%$, $26.2 \%, 8.5 \%$ and $4.04 \%$ than in healthy animals, respectively. The level of the contents such macro - and microelements as magnesium, sodium, iron and zinc in the healthy and infected animals was analogous ( $p>0.05)$.

The qualitative and quantitative changes of structure of amino acids composition of proteins were established in muscle tissue of sheep infected with cyst echinococcosis. It was revealed that the general content of amino acids in muscles of infected animals was lower, than in healthy sheep. The total amount of essential amino acids in samples from infected material, as a whole, was $4.5 \%$ lower, in comparison with healthy animals. Whereas the similar indicator for the nonessential amino acids was $1.5 \%$ lower (Table 4). Thus, it is established that in the muscle tissue of the sheep infected with E. granulosus, in comparison with healthy animals, the total of essential amino acids decreases by 3 times more than nonessential amino acids. The importance of these data is that the essential amino acids define a nutrition value of mutton more than does nonessential amino acids. Besides quantitative changes in the content of amino acids of muscle tissue of infected animals, there was observed a change of the amino acids profile of proteins of the studied tissue. Consequently, in the meat of sheep with echinococcosis, the most noticeable reduction occurred in the content of such essential amino acids, as valine (for 6.8\%) (p>0.05), arginine (6.1\%) $(\mathrm{p}<0.05)$, lysine $(5.8 \%)(\mathrm{p}>0.05)$, tryptophan and leucine (for 4.5\%) (p>0.05) (Table 4) in comparison with their content in protein of the muscle tissue of healthy animals.

The biochemical composition of fatty acids of muscle tissue of infected animals had deviations towards lower values in comparison with muscles of healthy sheep (Table $5)$. In the samples which were selected from infected sheep there was observed a significant $(\mathrm{p}<0.05)$ decrease in 
Table 4. Amount of amino acids in mutton

\begin{tabular}{|c|c|c|}
\hline \multirow[b]{2}{*}{ Indicators $(\mathrm{mg} / \mathrm{g})$} & \multicolumn{2}{|c|}{ Meat of animals } \\
\hline & $\begin{array}{c}\text { Infected by } \\
\text { echinococcosis }\end{array}$ & Healthy \\
\hline \multicolumn{3}{|l|}{ Essential amino acids } \\
\hline Arginine & $11.4 \pm 0.28$ & $12.14 \pm 0.41 *$ \\
\hline Valine & $10.22 \pm 0.47$ & $10.97 \pm 0.58$ \\
\hline Histidine & $6.04 \pm 0.51$ & $6.04 \pm 0.45$ \\
\hline Isoleucine & $9.02 \pm 0.21$ & $9.26 \pm 0.33$ \\
\hline Leucine & $14.28 \pm 0.56$ & $14.95 \pm 0.62$ \\
\hline Lysine & $15.59 \pm 0.38$ & $16.55 \pm 0.41$ \\
\hline Methionine & $4.20 \pm 0.32$ & $4.29 \pm 0.37$ \\
\hline Threonine & $7.99 \pm 0.51$ & $8.31 \pm 0.50$ \\
\hline Phenylalanine & $7.33 \pm 0.42$ & $7.60 \pm 0.54$ \\
\hline Tryptophan & $2.13 \pm 0.41$ & $2.23 \pm 0.50$ \\
\hline $\begin{array}{l}\text { Sum of essential } \\
\text { amino acids }\end{array}$ & 88.2 & 92.34 \\
\hline \multicolumn{3}{|l|}{ Nonessential amino acids } \\
\hline Alanine & $11.29 \pm 0.32$ & $11.28 \pm 0.41$ \\
\hline Asparagine & $17.93 \pm 0.13$ & $18.41 \pm 0.16^{*}$ \\
\hline Glycine & $8.88 \pm 0.19$ & $9.00 \pm 0.16$ \\
\hline Glutamine & $31.49 \pm 0.34$ & $32.18 \pm 0.45$ \\
\hline Proline & $8.55 \pm 0.29$ & $8.58 \pm 0.40$ \\
\hline Oxiproline & $3.42 \pm 0.27$ & $3.45 \pm 0.39$ \\
\hline Serine & $8.65 \pm 0.35$ & $8.79 \pm 0.41$ \\
\hline Tyrosine & $6.44 \pm 0.31$ & $6.47 \pm 0.41$ \\
\hline Cystine & $2.43 \pm 0.23$ & $2.45 \pm 0.25$ \\
\hline $\begin{array}{l}\text { Sum of nonessential } \\
\text { amino acids }\end{array}$ & 99.08 & 100.61 \\
\hline Sum of amino acids & 187.28 & 192.95 \\
\hline
\end{tabular}

amount of polyunsaturated acids, including linoleic for $7.9 \%(\mathrm{p}<0.05)$ and linolenic for $10.8 \%(\mathrm{p}<0.05)$ in comparison with healthy slaughtered animals. In compared groups monounsaturated myristoleic acid showed the highest rate of a difference (for 14.8\%) ( $\mathrm{p}<0.05$ ). Other studied saturated fatty acids of the muscle tissue showed significant $(\mathrm{p}<0.05)$, but a lower level of difference in the concentration between infected and healthy groups of animals. The amount of myristic, stearic and palmitic fatty acids in muscles of the infected animals was less $(\mathrm{p}<0.05)$ by $2.4 \%, 0.4 \%$ and $0.1 \%$ than in healthy animals, respectively.

\section{DISCUSSION}

Our research demonstrated that in the southeast of Kazakhstan the average contamination by E. granulosus hydatid cysts of slaughtered sheep at the age of 3 to 5 years, which are sold through the markets of Almaty, is $9.68 \%$. Intensity of an invasion by fertile echinococcus larvae
Table 5. Amount of fatty acids in mutton

\begin{tabular}{|c|c|c|}
\hline \multirow[b]{2}{*}{ Indicators (mg/100 g) } & \multicolumn{2}{|c|}{ Meat of animals } \\
\hline & $\begin{array}{c}\text { Infected by } \\
\text { echinococcosis }\end{array}$ & Healthy \\
\hline Saturated & $4,238.5 \pm 0.48$ & $4,254.8 \pm 1.98 *$ \\
\hline $\mathrm{C}_{14: 0}$ (myristic) & $310.1 \pm 0.29$ & $317.6 \pm 0.51 *$ \\
\hline $\mathrm{C}_{16: 0}$ (palmitic) & $2,044.5 \pm 0.17$ & $2,046.8 \pm 0.58 *$ \\
\hline $\mathrm{C}_{18: 0}($ stearic $)$ & $1,883.8 \pm 0.4$ & $1,890.4 \pm 1.08 *$ \\
\hline Monounsaturated & $3,512.5 \pm 0.65$ & $3,526.2 \pm 1.36^{*}$ \\
\hline $\mathrm{C}_{14: 1}$ (myristoleic) & $45.3 \pm 0.37$ & $53.2 \pm 0.37^{*}$ \\
\hline $\mathrm{C}_{16: 1}$ (palmitoleic) & $197.1 \pm 0.29$ & $203.0 \pm 0.71 *$ \\
\hline $\mathrm{C}_{18: 1}($ oleic $)$ & $3,270.3 \pm 0.27$ & $3,270.0 \pm 0.71$ \\
\hline Polyunsaturated & $296.9 \pm 0.30$ & $326.0 \pm 0.89 *$ \\
\hline $\mathrm{C}_{18: 2}$ (linoleic) & $194.7 \pm 0.33$ & $211.4 \pm 0.51 *$ \\
\hline $\mathrm{C}_{18: 3}(\alpha$-linolenic $)$ & $102.2 \pm 0.26$ & $114.6 \pm 0.4 *$ \\
\hline Amount of fatty acids & $8,048.1 \pm 1.12$ & $8,107.0 \pm 3.49 *$ \\
\hline
\end{tabular}

varies within 3 to 4 cysts on the organ. Parasites are mainly found in liver and lungs (in $98.5 \%$ of animals). In other isolated cases there were observed multiple echinococcoses with simultaneous infection of kidneys or spleens. The incidence of E. granulosus infection in adult sheep did not display large fluctuations on seasons of the year. In our opinion, this is explained by the constant character of the invasion by oncospheres during the life time of the sheep. Accordingly, the lowest prevalence of infection of sheep established during summer and autumn seasons of year. Other scientists (Ansari-Lari, 2005; Latif et al., 2010) also observed that echinococcosis is still highly endemic in the region of Central Asia. They found that the prevalence of hydatic cysts in slaughtered sheep was $7.52 \%$ to $14.62 \%$.

The present results agree with the opinion in the literature that echinococcosis has the wide circulation among sheep and is an actual problem for the regional veterinary medicine (Torgenson et al., 2002; Shaikenov et al., 2003). In particular, a very practical interest for veterinians and meat inspector is to define the effect of echinococcosis on the quality and quantitative indices of the meat.

It is known that the pathogenic influence of helminths has a serious affect on the tissues of an infected organism. It has been experimentally demonstrated that helminthoses cause the reduction of the content of general protein in liver, muscles, blood and other tissues, damage to carbohydrate and fatty exchanges, the decrease in the contents in organs of A, C vitamins and disruption to the exchange of B-group vitamins (Yampolskiy, 1981).

Studies of the chemical composition of meat and meat products of cattle infected with echinococcosis established that the maintenance of protein and fat decreases, and moisture increases. The liver and other organs of cattle with 
echinococcosis display serious pathology compared to organs of healthy animals (Blochina, 2009). Our research show that when echinococcosis is present, even the histologic structure of the muscle tissue of sheep exhibits noticeable destructive changes with a prevalence of granular dystrophy.

The results of the current study have shown that nutrient composition, fatty acid profile, levels of amino acids, vitamins and mineral elements in meat from healthy animals differ in results obtained from various regions of the world (Lewis et al., 1995; Brzostowski et al., 2004; Williams, 2007). Williams (2007) indicated that nutritional composition of mutton depends on breed of sheep, feed, season and cut of meat.

The biochemical analysis also showed that in the mutton from sheep infected by hydatidosis, in comparison with muscle tissue of healthy animals, the amount of protein, fat and calcium, calorific value significantly decrease. Besides, in the meat of animals infected with echinococcosis there is a substantial increase of humidity and amount of ashes. These results testify that in the sheep, echinococcosis causes a complex of biochemical changes.

The present results reveal a significant change in the quality and quantity of the amino acids profile of proteins in the muscle tissue of sheep infected with echinococcosis. This is connected, in our opinion, with localization of echinococcosis cysts. As all samples of the studied muscles were selected from sheep with infected livers, for this reason there were disruptions in regulation of protein exchange in the presence of helminth larvae.

Along with disruption of the synthesis of proteins and the vitamin balance, in particular, the sharp insufficiency of vitamins $A, E, B_{1}$, and $B_{2}$, there were observed shifts in a lipidic exchange that was expressed as a noticeable reduction of the monounsaturated and polyunsaturated fatty acids level. It is known that the development of $E$. granulosus cysts is carried out by the intensive expense of lipids of the host (Porfido et al., 2012), and this explains the decrease in the concentration of fatty acids in tissues of the infected organism.

Other scientists (Torgenson, 2003; Ansari-Lari, 2005) also indicated that cystic echinococcosis cause economic losses not only from the condemnation of infected viscera, but also from decreases in yield and quality of meat and delayed performance and growth.

\section{CONCLUSION}

The specified biochemical changes in the muscle tissue of infected sheep are the cause of the decrease in the biological value of meat. Results of the present research allow concluding that the meat from the sheep infected with echinococcosis is of poorer quality to the muscle tissue of the healthy animal as well as being biologically inferior.

\section{REFERENCES}

Ansari-Lari, M. 2005. A retrospective survey of hydatidosis in livestock in Shiraz, Iran, based on abattoir data during 19992004. Vet. Parasitol. 133:119-123.

AOAC. 1990. Official methods of analysis. $15^{\text {th }}$ ed. Association of official analytical chemists, inc. Arlington, USA.

Brzostowski, H., J. Tywonczuk, and Z. Tanski. 2004. Indexes of nutritive value of meat obtained from Pomeranian lambs and crossbreeds of Pomeranian ewes with meet breed rams. Arch. Tierz. 47:175-182.

Budke, C. M., P. Deplazes, and P. R. Torgerson. 2006. Global socioeconomic impact of cystic echinococcosis. Emerg. Infect. Dis. 12:296-303.

Borji, H., M. Azizzadeh, and M. A. Kamelli. 2012. Retrospective study of abattoir condemnation due to parasitic infections: economic importance in Ahwaz, southwestern Iran. J. Parasitol. 98:954-957.

Bergstrom, R. C., J. L. Kinnison, and B. A. Werner. 1977. Parasitism (Trichostrongylus colubriformis and Eimeria ninakohlyakimovae) in sheep: relationship between wool fiber diameter changes and feed conversion efficiency. Am. J. Vet. Res. 38:887-888.

Blochina, S. V. 2009. Epizootology of cystic echinococcosis in Omsk region. Ph.D. Thesis, Tyumen, 142 p. - In Russian.

Carson, F. L. 1997. Histotechnology: a self-instructional text. Chicago, American Society for Clinical pathology, 6:93.

Ernest, E., H. E. Nonga, A. A. Kassuku, and R. R. Kazwala. 2009. Hydatidosis of slaughtered animals in Ngorongoro district of Arusha region, Tanzania. Trop. Anim. Health Prod. 41:11791185.

Folch, J., M. Lees, and G. H. Sloane Stanley. 1957. Isolation and purification of a simple method for the total lipides from animal tissues. J. Biol. Chem. 226:497-509.

Getaw, A., D. Beyene, D. Ayana, B. Megersa, and F. Abunna. 2010. Hydatidosis: prevalence and its economic importance in ruminants slaughtered at Adama municipal abattoir, Central Oromia, Ethiopia. Acta Trop. 113:221-225.

ISO 5509. 1978. Animal and vegetable fats and oils - Preparation of methyl esters of fatty acids.

Knecht, D., A. Jankowska, and G. Zaleśny. 2012. The impact of gastrointestinal parasites infection on slaughter efficiency in pigs. Vet Parasitol. 184:291-297.

Latif, A. A., A. Tanveer, M. Azhar, N. Siddiqi, M. Kyaw-Tanner, and R. J. Traub. 2010. Morphological and molecular characterization of Echinococcus granulosus in livestock and humans in Punjab, Pakistan. Vet. Parasitol. 170:44-49.

Lewis, J., G. Milligan, and A. Hurt. 1995. NUTTAB 95 - Nutrient data table for use in Australia. Food Standarts Australia New Zealand. Commonwealth of Australia. Vol. 1.

Porfido, J. L., G. Alvite, V. Silva, M. W. Kennedy, A. Esteves, and B. Corsico. 2012. Direct interaction between EgFABP1, a fatty acid binding protein from Echinococcus granulosus, and phospholipid membranes. PLoS Negl Trop. Dis. 6(11):e1893.

Romig, T., A. Dinkel, and U. Mackenstedt. 2006. The present 
situation of echinococcosis in Europe. Parasitol. Int. 55:S187191.

Shaikenov, B. S., P. R. Torgerson, A. E. Usenbayev, K. K. Baitursynov, A. T. Rysmukhambetova, A. M. Abdybekova, and K. O. Karamendin. 2003. The changing epidemiology of echinococcosis in Kazakhstan due to transformation of farming practices. Acta Trop. 85:287-293.

Torgerson P., B. Shaikenov, and O. Kuttybaev. 2002. Cystic echinococcosis in Central Asia: new epidemic in Kazakhstan and Kyrgystan. In: Cestode zoononoses: echinococcosis and cysticercosis, and emergent and global problem (Ed. P. Craig and Z. Pawlowski). IOS Press, Amsterdam, Netherlands, 99105.

Torgerson, P. R. 2003. Economic effects of echinococcosis. Acta Trop. 85:113-118.
Torgerson, P. R., P. R. Karaeva, N. Corkeri, T. A. Abdyjaparov, and O. T. Kuttubaev. 2003. Human cystic echinococcosis in Kyrgystan: an epidemiological study. Acta Trop. 85:51-61.

Torgerson, P. R., B. Oguljahan, A. E. Muminov, R. R. Karaeva, O. T. Kuttubaev, M. Aminjanov, and B. Shaikenov. 2006. Present situation of cystic echinococcosis in Central Asia. Parasitol. Int. 55:S207-S212.

Theodoropoulos, G., E. Theodoropoulou, G. Petrakos, V. Kantzoura, and J. Kostopoulos. 2002. Abattoir condemnation due to parasitic infections and its economic implications in the region of Trikala, Greece. J. Vet. Med. B Infect. Dis. Vet. Public Health 49:281-284.

Yampolskiy, B. V. 1981. Sanitary assessment and quality of carcasses and organs of cattle with echinococcosis. Ph.D. Thesis. Odessa, p. 181. In Russian.

Williams, P. G. 2007. Nutritional composition of red meat. Nutr. Diet. 64:S113-S119. 